\title{
Iron oxide mineralogy in red and brown soils developed on calcareous rocks in central Italy
}

A. Mirabella ${ }^{\mathrm{a}}$,

S. Carnicelli ${ }^{\text {b }}$

${ }^{a}$ Istituto Sperimentale per lo Studio e la Difesa del Suolo, P.zza D'Azeglio 30, 50131 Firenze, Italy

${ }^{\mathrm{b}}$ Università degli Studi di Firenze, Dipartimento di Scienza del Suolo e Nutrizione della Pianta, P. le Cascine 15, 50144 Firenze, Italy

\section{Abstract}

Samples of 9 red and brown closely associated soils developed from highly calcareous materials in central Tuscany, Italy, were analyzed to determine: the mineralogical properties of the iron oxides, the relationship between redness and hematite content, and the relationship between parent material and iron oxide mineralogy.

Goethite and hematite were the only crystalline iron oxides detected in the A, E and B horizons studied. X-ray data indicated that they were either poorly crystalline or of small particle size. A high proportion (67 to $95 \%$ ) of the total iron was extracted by dithionite, and oxalate-extractable Fe was less than $10 \%$ of Fed in most of the samples. The extent of Al substitution in goethite was positively correlated $(\mathrm{R} 2=0.68)$ to crystal dimension along the 110 direction. This finding is consistent with those for aluminous goethites synthesized at $25^{\circ} \mathrm{C}$ but at odds with some published data for natural goethites.

Redness rating of dry crushed samples, as determined with Munsell colour charts, was positively correlated $(\mathrm{R} 2=0.79)$ with hematite content. Redness rating, however, would provide only a crude estimate of hematite content.

The soils with the lowest content of total iron had by far the lowest hematite content; nearly all of the crystalline iron oxide was goethite. This lends support to the hypothesis that parent material influences the development of iron oxides in soils. 